\title{
BMJ Open Socioeconomic inequalities in obesity: modelling future trends in Australia
}

\author{
Alison Hayes, ${ }^{1}$ Eng Joo Tan, ${ }^{\oplus 1}$ Anagha Killedar, ${ }^{1}$ Thomas Lung ${ }^{2}$
}

To cite: Hayes A, Tan EJ, Killedar A, et al. Socioeconomic inequalities in obesity: modelling future trends in Australia. BMJ Open 2019;9:e026525. doi:10.1136/ bmjopen-2018-026525

- Prepublication history and additional material for this paper are available online. To view these files, please visit the journal online (http://dx.doi. org/10.1136/bmjopen-2018026525).

Received 6 September 2018 Revised 14 February 2019 Accepted 18 February 2019

Check for updates

(C) Author(s) (or their employer(s)) 2019. Re-use permitted under CC BY-NC. No commercial re-use. See rights and permissions. Published by BMJ.

${ }^{1}$ School of Public Health, Faculty of Medicine and Health, The University of Sydney, NSW, Australia

${ }^{2}$ The George Institute for Global Health, University of New South Wales, Sydney, Australia

Correspondence to

Dr Eng Joo Tan;

a.tan@sydney.edu.au

\section{ABSTRACT}

Objectives To develop a model to predict future socioeconomic inequalities in body mass index (BMI) and obesity.

Design Microsimulation modelling using BMI data from adult participants of Australian Health Surveys, and published data on the relative risk of mortality in relation to BMI and socioeconomic position (SEP), based on education.

Setting Australia.

Participants 74329 adults, aged 20 and over from Australian Health Surveys, 1995-2015.

Primary and secondary outcome measures The primary outcomes were BMI trajectories and obesity prevalence by SEP for four birth cohorts, born 10 years apart, centred on 1940, 1950, 1960 and 1970.

Results Simulations projected persistent or widening socioeconomic inequality in BMI and obesity over the adult life course, for all birth cohorts. Recent birth cohorts were predicted to have greater socioeconomic inequality by middle age, compared with earlier cohorts. For example, among men, there was no inequality in obesity prevalence at age 60 for the 1940 birth cohort (low SEP 25\% (95\% Cl $17 \%$ to $34 \%$ ); high SEP $26 \%$ (95\% Cl $19 \%$ to $34 \%)$ ), yet for the 1970 birth cohort, obesity prevalence was projected to be $51 \%$ (95\% Cl $43 \%$ to $58 \%$ ) and $41 \%$ (95\% Cl $36 \%$ to $46 \%$ ) for the low and high SEP groups, respectively. Notably, for more recent birth cohorts, the model predicted the greatest socioeconomic inequality in severe obesity $\left(\mathrm{BMI}>35 \mathrm{~kg} / \mathrm{m}^{2}\right)$ at age 60 .

Conclusions Lower SEP groups and more recent birth cohorts are at higher risk of obesity and severe obesity, and its consequences in middle age. Prevention efforts should focus on these vulnerable population groups in order to avoid future disparities in health outcomes. The model provides a framework for further research to investigate which interventions will be most effective in narrowing the gap in socioeconomic disparities in obesity in adulthood.

\section{INTRODUCTION}

Obesity has been described as the public health challenge of our time. ${ }^{1}$ In the last four decades, high-income Western countries including Australia have seen unprecedented increases in age-standardised adult BMI and the prevalence of obesity. ${ }^{2}$ More recently, severe obesity $\left(\mathrm{BMI}>35 \mathrm{~kg} / \mathrm{m}^{2}\right)$ has emerged as a public health problem, and in Australia the prevalence has doubled in the last 20 years
Strengths and limitations of this study

- This is an innovative study and the first to use microsimulation to increase our understanding of trends in socioeconomic disparities in body mass index (BMI) and obesity among adults in Australia.

- The model combines the best evidence pertaining to obesity progression and mortality in different socioeconomic groups and includes Australian data, and published meta-analyses of mortality in relation to weight status and socioeconomic position (SEP).

- The model has been presented transparently and externally validated using the most recently available national data on population-level adult BMI from Australia.

- A limitation is the use of only one indicator of SEP based on educational attainment, which had some missing data in the baseline population.

(from $5 \%$ to $10 \%$ of the adult population). ${ }^{3}$ This has important implications, because the upper extremes of the BMI spectrum confer acute health risks and because healthcare costs rise steeply with BMI above $35 \mathrm{~kg} / \mathrm{m}^{2}$.

It is well established that in high-income countries, obesity disproportionately affects the most socioeconomically disadvantaged groups. ${ }^{5}$ Furthermore, there are major disparities in chronic disease outcomes for which overweight and obesity is a risk factor. ${ }^{6}$ However, the current literature pertaining to high-income countries is conflicting on whether inequalities in obesity are persistent, ${ }^{7}$ widening ${ }^{8}$ or narrowing. ${ }^{9} 10$

People generally accrue BMI during their life course ${ }^{11}$ and, as a result, there has been great interest in identifying BMI trajectories through longitudinal studies or modelling BMI growth trajectories ${ }^{12}$ to understand the epidemiology of disease and to identify at-risk populations. Beyond their value in epidemiological studies, models are regarded as powerful tools for informing policy decisions, ${ }^{13}$ yet current models of obesity rarely take account of socioeconomic position (SEP), thus overlooking a key policy-relevant determinant of obesity. There are currently few analytical tools to evaluate which 
interventions are most effective in reducing inequalities. ${ }^{14}$ Simulation models may provide insights in this context that are not possible with traditional statistical methods, ${ }^{15}$ but their use is just beginning. ${ }^{16}$

In this study, we present a new version of a microsimulation model for Australia adults ${ }^{17}$ which projects obesity in different socioeconomic subgroups, based on educational attainment. In microsimulation, individuals are modelled separately, and these methods are well established in health economics as a way of predicting outcomes based on individual characteristics. ${ }^{18}$ An important consideration before gaining insights from a model is that it predicts consistently across SEP groups. ${ }^{14}$ Accordingly, in this study, we validate our model projections against observed BMI trajectories and obesity progression, stratified by SEP, and then use the model to determine future trends in socioeconomic inequalities in obesity — both within and between generations.

\section{METHODS}

\section{Study populations}

Study populations included survey respondents of four Australian National Health Surveys between 1995 and 2015, including the 1995 National Nutrition Survey (NNS) and National Health Surveys in 2007/2008, 2011/2012 and 2014/2015. ${ }^{3}{ }^{19-21}$ Height and weight were objectively measured by trained interviewers and participation was voluntary. A stadiometer was used to measure height to a maximum of $210 \mathrm{~cm}$ and correct to one decimal point. Weight was measured using digital scales measuring to a maximum of $139.9 \mathrm{~kg}$ (1995 survey) and to a maximum of $150 \mathrm{~kg}$ (later surveys) and reported correct to one decimal point. Body mass index (BMI) was determined from weight in $\mathrm{kg}$ divided by height in metres squared $\left(\mathrm{m}^{2}\right)$. SEP was based on completion of high school and derived from responses to the survey question 'whether completed secondary school' in NNS 1995 and 'highest year of school completed' for subsequent health surveys $(2007 / 2008$ and beyond). Data from the 1995 and 2011/2012 surveys were used to derive equations for age-related annual weight gain, and all health surveys beyond 1995 were used in validation of model predictions until 2014/2015.

\section{Overview of the simulation model}

Our approach uses individual-level (microsimulation) modelling and predicts BMI trajectories for members of the Australian adult population. Microsimulation accounts for heterogeneity within a population and thus can model obesity progression based on individual characteristics such as age, sex and SEP. The model is initialised with nationally representative individual-level data from participants of national health surveys that have characteristics of age, sex, SEP and measured BMI. The model runs on discrete time steps, in which individuals grow older by 1 year, they may gain or lose weight and/or they may die in any annual cycle. BMI is modelled as a continuous variable, age is modelled in individual years and SEP is a binary variable defined by completion of high school. The model equations predicting annual BMI change (online supplementary methods 1.1) are based on Australian national data, using a synthetic cohort technique. ${ }^{22}$ The modelling of age, sex and SEP-specific mortality (online supplementary methods 1.2 ) is based on the $2011 / 2012$ Australian life table, ${ }^{23} \mathrm{a}$ published meta-analysis of the association of BMI and all-cause mortality, ${ }^{24}$ and the published relative risk of mortality by SEP from a large Australian cohort study. ${ }^{25}$ This involves apportioning the conditional probability of death to those of different weight status and SEP, using established methods. ${ }^{26}$

\section{Validation and prediction of BMI and obesity trajectories by SEP}

We carried out validation of the model predictions, for four birth cohorts 1966-1975, 1956-1965, 1946-1955 and 1936-1945 (centred around 1970, 1960, 1950 and 1940 and aged 20-29, 30-39, 40-49 and 50-59 years in 1995). Starting with a baseline population representing 4.5 million adult men and 4.9 million adult women in 1995, we simulated BMI trajectories and determined the prevalence of healthy, overweight, obesity and severe obesity over three decades to 2025, stratified by SEP. Predicted mean BMI and prevalence of weight status groups, using standard BMI cut-points, were compared with health survey data from 2007/2008, 2011/2012 and $2014 / 2015$, matched to the same birth cohorts. As only the 1995 and 2011/2012 data were used in the derivation of model equations, this represents both internal and external validation. ${ }^{27}$ Survey estimation (svy command in STATA) was used throughout the analysis of health survey data and when preparing summary results of simulated data. These weights take account of the multistage sampling, and summary data such as mean BMI or prevalence of obesity can be inferred at a population level.

\section{SEP inequalities in BMI and obesity by birth cohort}

We simulated BMI trajectories from 1995 to 2035 to predict how the population BMI distribution and obesity prevalence progresses over time among different birth cohorts and different SEP groups. In order to compare outcomes of different birth cohorts at a common age, we ran simulations over the adult life course. We chose 60 years as a suitable age to compare outcomes, as this is the age at which obesity-related chronic disease starts to become apparent.$^{28}$ For the two most recent birth cohorts, this required running simulations prospectively, that is, beyond 2015. We then determined inequality, calculated as differences between high and low SEP in mean BMI, prevalence of obesity (BMI $>30 \mathrm{~kg} / \mathrm{m}^{2}$ ) and prevalence of severe obesity $\left(\mathrm{BMI}>35 \mathrm{~kg} / \mathrm{m}^{2}\right)$ at age 60 years.

\section{Sensitivity analysis}

Sensitivity analysis seeks to identify sensitive model parameters, that is, those which are most important in driving 

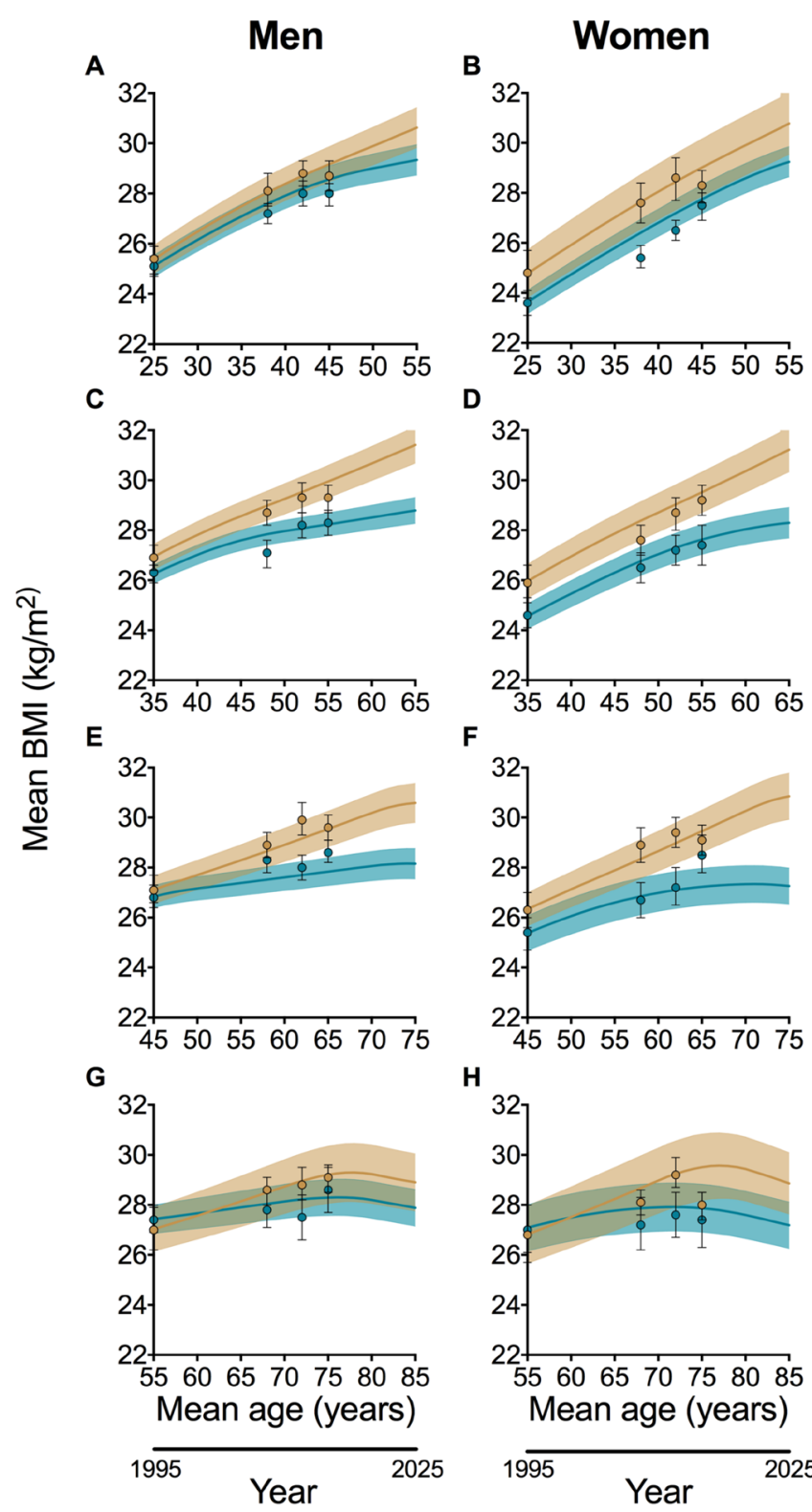

H

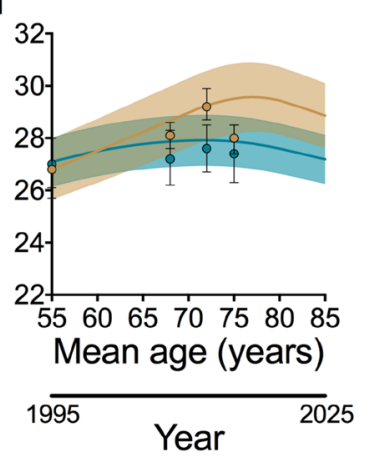

Data 95\% Cl (low SEP) - Model mean 95\% Cl (low SEP)

Data $95 \% \mathrm{Cl}$ (high SEP)

Model mean $95 \% \mathrm{Cl}$ (high SEP)

Figure 1 Simulated compared with actual BMI trajectories for four birth cohorts stratified by SEP. (A) Birth cohort 19661975 for men, (B) birth cohort 1966-1975 for women, (C) birth cohort 1956-1965 for men, (D) birth cohort 1956-1965 for women, (E) birth cohort 1946-1955 for men, (F) birth cohort 1946-1955 for women, (G) birth cohort 1936-1945 for men, (H) birth cohort 1936-1945 for women. Lines=simulated BMI trajectory and $95 \% \mathrm{Cl}$; circles=observed mean $(95 \% \mathrm{Cl}) \mathrm{BMI}$ from national health surveys; turquoise=high SEP; brown=low SEP. BMI, body mass index; SEP, socioeconomic position.

model outputs. ${ }^{29}$ We changed major model parameters by their upper and lower $95 \%$ confidence limits and observed the change in the projected prevalence of mean BMI, overall obesity and severe obesity by age 60 years, when compared with the base model. These sensitivity analyses were carried out for men and women of high and low SEP, for four different age and birth cohorts, centred around: 1940, 1950, 1960 and 1970.

Parameters investigated in the one-way sensitivity analyses were:

a. Changing constants in the weight gain equations for men and women, by upper and lower $95 \%$ confidence limits.

b. Changing the HR for mortality (1.39 (95\% CI 1.08 to 1.79)) of low compared with high education groups by the upper and lower $95 \%$ confidence limits.

Further details are provided in online supplementary methods 1.3 .

\section{Patient and public involvement}

Patients and public were not involved in the design of the research study. This study is a modelling study that used non-identifiable participant data from National Health Surveys and collected under the Census Act.

\section{RESULTS \\ Validation and projection of BMI and obesity trajectories by SEP}

Figure 1 shows simulated and observed BMI trajectories between 1995 and 2025 for four birth cohorts of men and women and two SEP groups. Overall, simulated BMI trajectories predicted a widening or persisting socioeconomic inequality in mean BMI over time. For all cohorts, the model showed good internal and external validation as health survey data were within the simulated 95\% CI.

Similarly, inequalities in the prevalence of obesity were also projected to widen over time, and this widening appeared to be greatest for the 1950 and 1960 birth cohorts (at least until 2025) which was corroborated by survey data for each birth cohort (figure 2). Validation graphs of more weight status groups by SEP are shown in online supplementary figures 1 and 2 .

\section{SEP inequalities in BMI and obesity by birth cohort}

Figure 3 shows an example of the simulated progression of BMI distribution over time, for high and low SEP, starting with a base population of 20-29 years men. The baseline BMI distribution of the low SEP group was already flattered and more right skewed than the high SEP group in 1995. Simulated data show that by 2015 the distributions have advanced and the right skew increased but this is more pronounced for low SEP. By 2035, the right skew is projected to increase further, resulting in greater proportion of the distribution above BMI $>35 \mathrm{~kg}$ / $\mathrm{m}^{2}$ for low compared with high SEP.

The model predicted that recent birth cohorts will experience unprecedented levels of obesity and severe obesity by the time they reach middle age (figure 4)and the lower SEP group will be worst affected. Obesity at age 60 (represented by total bar height in figure 4) is predicted to be higher for each successive birth cohort. For the 1970 birth cohort, the model predicts that $50 \%$ of the low SEP group and around $40 \%$ of the high SEP will 

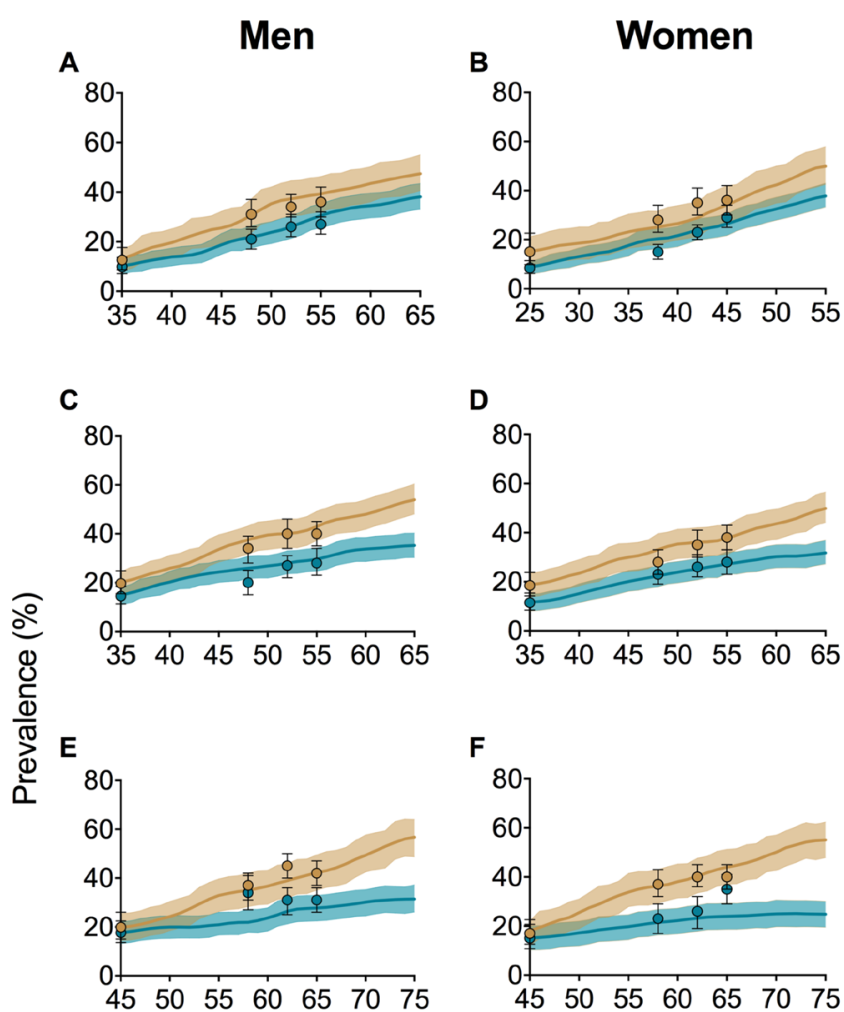

D

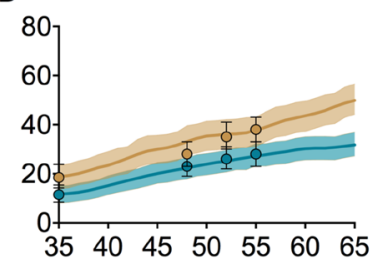

$\mathbf{F}$

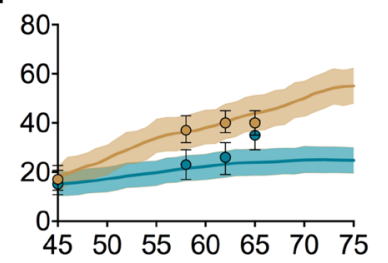

G

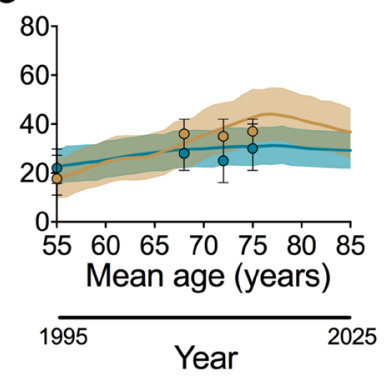

H

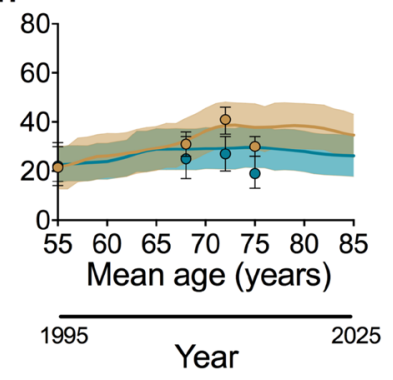

O Data 95\% Cl (low SEP) — Prevalence (\%) 95\% Cl (low SEP) - Data $95 \% \mathrm{Cl}$ (high SEP) — Prevalence (\%) 95\% Cl (high SEP)

Figure 2 Simulated compared with actual obesity $\left(\mathrm{BMI}>30 \mathrm{~kg} / \mathrm{m}^{2}\right)$ prevalence for four birth cohorts stratified by SEP. (A) Birth cohort 1966-1975 for men, (B) birth cohort 1966-1975 for women, (C) birth cohort 1956-1965 for men, (D) birth cohort 1956-1965 for women, (E) birth cohort 19461955 for men, (F) birth cohort 1946-1955 for women, (G) birth cohort 1936-1945 for men, (H) birth cohort 1936-1945 for women. Lines=simulated obesity prevalence and $95 \% \mathrm{Cl}$; circles $=$ observed obesity prevalence $(95 \% \mathrm{Cl})$ from national health surveys; turquoise=high SEP; brown=low SEP. BMI, body mass index; SEP, socioeconomic position.

have obesity at age 60 years, approximately double that of the 1940 birth cohort of around 24\%, irrespective of SEP. Substantial socioeconomic inequalities in mean BMI and prevalence of obesity at age 60 years were predicted for the three most recent cohorts studied (table 1); a difference of 1-2 units of BMI, and 10\%-15\% obesity prevalence between low and high SEP. In contrast, there was virtually no inequality in any of the outcomes at age 60 for the 1940 birth cohort. While socioeconomic inequalities
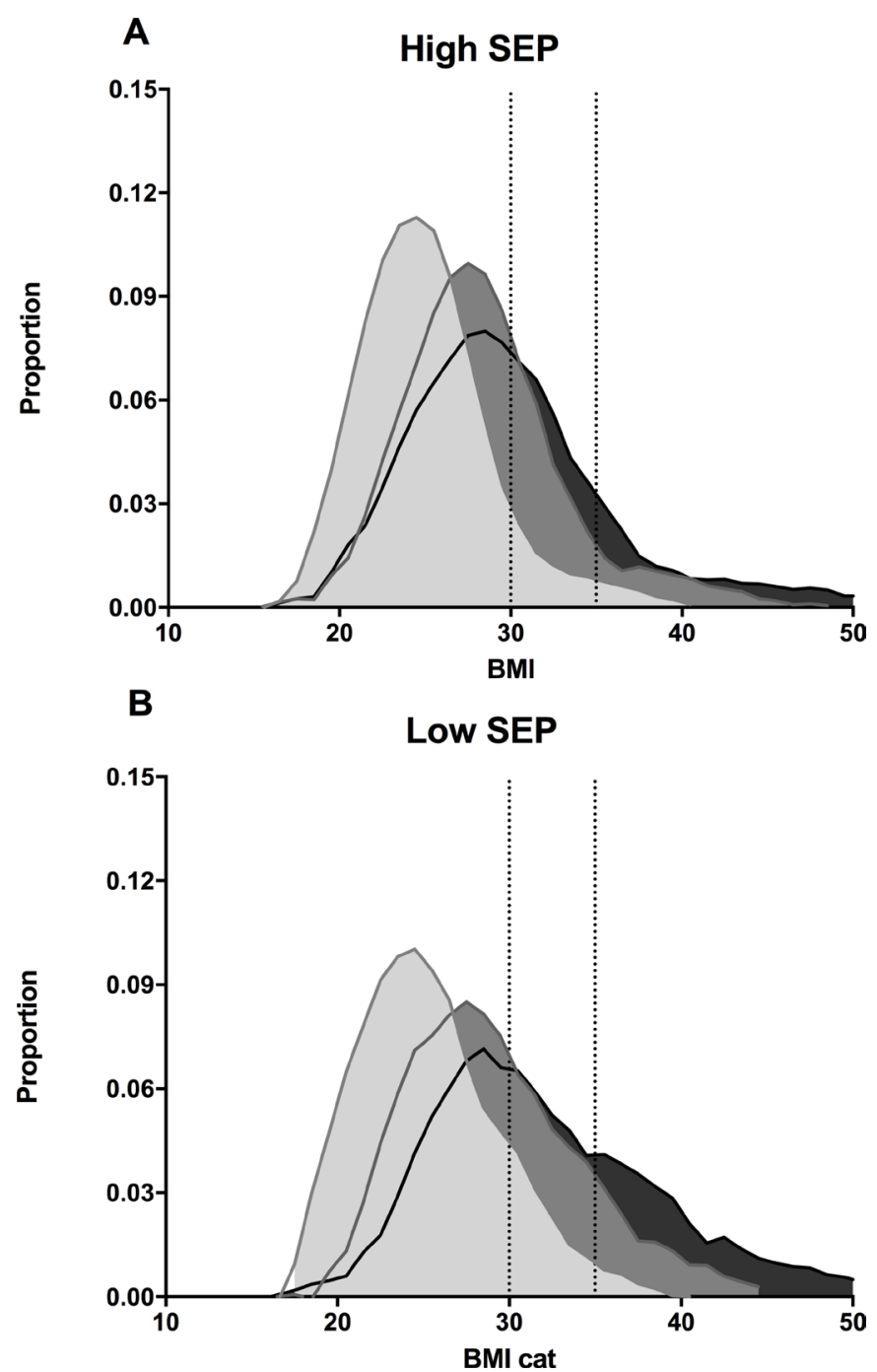

Figure 3 Simulated BMI distributions in 1995, 2015 and 2035 for men, 1966-1975 birth cohort. (A) High SEP (B) Low SEP. Light grey=1995; dark grey=2015; black=2035. Dotted lines represent obesity and severe obesity cut-points. BMI, body mass index; SEP, socioeconomic position.

in BMI and obesity $(\mathrm{BMI}>30)$ at age 60 were predicted to widen for the two successive birth cohorts beyond 1940, there was some attenuation of these inequalities for the 1970 cohort (table 1$)$.

Notably, for the two most recent birth cohorts investigated (1960 and 1970), socioeconomic inequality at age 60 years was predicted to be greatest in severe obesity (BMI $>35 \mathrm{~kg} / \mathrm{m}^{2}$ ), with a difference of about $10 \%$ points between high and low SEP groups (figure 4). In contrast, there was negligible inequality in obesity $(30 \mathrm{~kg} /$ $\mathrm{m}^{2}>\mathrm{BMI}<35 \mathrm{~kg} / \mathrm{m}^{2}$ ) between high and low SEP groups of the same birth cohorts. In other words, most of the predicted socioeconomic inequality in BMI above $30 \mathrm{~kg}$ / $\mathrm{m}^{2}$ is due to inequality at the extreme upper bound $\left(\mathrm{BMI}>35 \mathrm{~kg} / \mathrm{m}^{2}\right)$.

\section{Sensitivity analysis}

The results of the sensitivity analyses are shown in online supplementary methods 1.3. Changing annual 


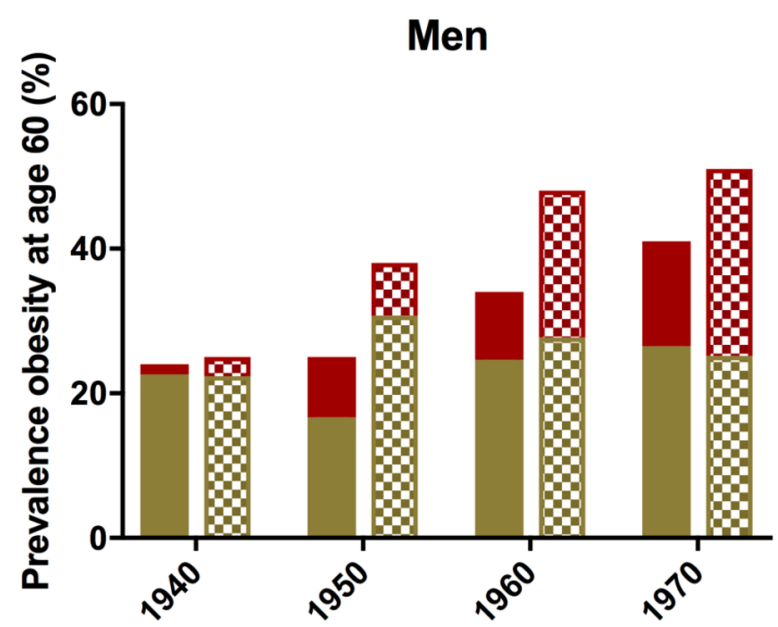

Birth cohort

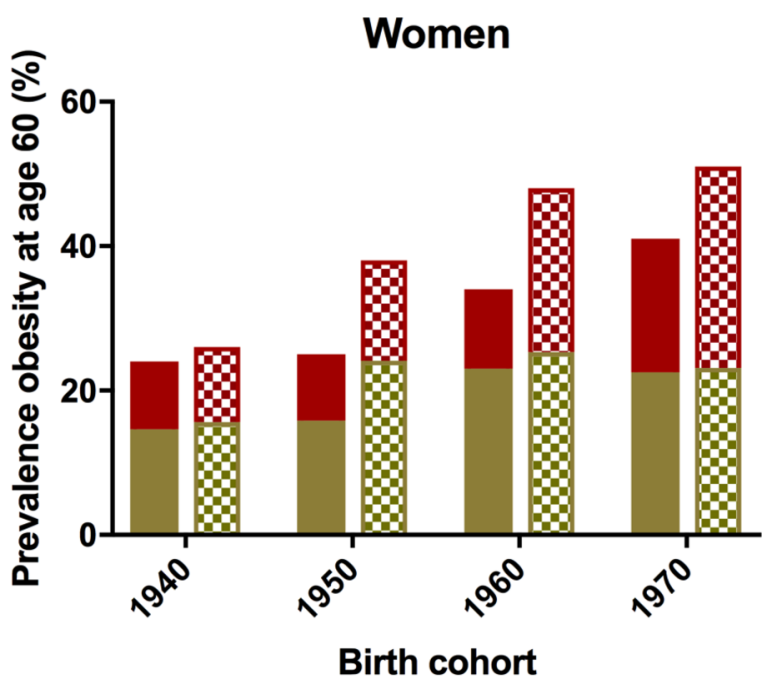

[10. Obese only (low SEP)

Obese only (high SEP)

Figure 4 Simulated prevalence of obesity and severe obesity at age 60 for different birth cohorts, men and women brown=obesity $\left(30<\mathrm{BMl}<35 \mathrm{~kg} / \mathrm{m}^{2}\right)$; red=severe obesity $\left(\mathrm{BMl}>35 \mathrm{~kg} / \mathrm{m}^{2}\right)$; solid bars=high SEP; hatched bars=low SEP. BMI, body mass index; SEP, socioeconomic position.

weight gain by upper and lower CIs had major impacts on predicted BMI, obesity and severe obesity at age 60, but only minimal effects on inequalities. For example, the prevalence of obesity at age 60 for the 1970 cohort changed by approximately $+25 \%$ or $-19 \%$ under the alternate weight gain scenarios, yet the inequalities increased only slightly, by $3 \%-5 \%$. Furthermore, changing the hazard of mortality by SEP to upper and lower 95\% CI had little or no effect on projected mean BMI, obesity and severe obesity at age 60 years, and no effect on absolute inequalities. None of the sensitivity analyses investigated affected the predicted pattern of obesity being higher with successive generations and the finding that the three most recent cohorts would have greater socioeconomic

Table 1 Simulated outcomes at age 60 for different birth cohorts of men and women, and difference (inequality) in outcomes between lower and higher SEP groups (high minus low)

\begin{tabular}{|c|c|c|c|c|c|c|c|c|c|}
\hline \multirow{2}{*}{$\begin{array}{l}\text { Birth } \\
\text { cohort }\end{array}$} & \multicolumn{3}{|c|}{$\begin{array}{l}\text { Mean }(95 \% \mathrm{Cl}) \mathrm{BMI} \text { at age } 60 \\
\left(\mathrm{~kg} / \mathrm{m}^{2}\right)\end{array}$} & \multicolumn{3}{|c|}{$\begin{array}{l}\text { Obesity }\left(\mathrm{BMI}>30 \mathrm{~kg} / \mathrm{m}^{2}\right) \text { prevalence }(\%) \text { and } \\
95 \% \mathrm{Cl}\end{array}$} & \multicolumn{3}{|c|}{$\begin{array}{l}\text { Severe obesity }\left(\mathrm{BMI}>35 \mathrm{~kg} / \mathrm{m}^{2}\right) \\
\text { Prevalence }(\%) \text { and } 95 \% \mathrm{Cl}\end{array}$} \\
\hline & Low SEP & High SEP & Difference & Low SEP & High SEP & Difference & Low SEP & High SEP & Difference \\
\hline \multicolumn{10}{|l|}{ Men } \\
\hline 1940 & $\begin{array}{l}27.6 \\
(26.6 \text { to } 28.5)\end{array}$ & $\begin{array}{l}27.7 \\
(27.1 \text { to } 28.3)\end{array}$ & $\begin{array}{l}0.1 \\
(-1.0 \text { to } 1.2)\end{array}$ & $\begin{array}{l}24.5 \\
(15.5 \text { to } 33.4)\end{array}$ & $\begin{array}{l}25.6 \\
(18.2 \text { to } 33.0)\end{array}$ & $\begin{array}{l}1.1 \\
(0.7 \text { to } 1.5)\end{array}$ & $\begin{array}{l}1.4 \\
(0.0 \text { to } 2.9)\end{array}$ & $\begin{array}{l}2.6 \\
(0.3 \text { to } 4.8)\end{array}$ & $\begin{array}{l}1.2 \\
(0.9 \text { to } 1.5)\end{array}$ \\
\hline 1950 & $\begin{array}{l}28.9 \\
(28.2 \text { to } 29.6)\end{array}$ & $\begin{array}{l}27.6 \\
(27.1 \text { to } 28.1)\end{array}$ & $\begin{array}{l}-1.3 \\
(-2.2 \text { to }-0.5)\end{array}$ & $\begin{array}{l}36.3 \\
(29.3 \text { to } 43.2)\end{array}$ & $\begin{array}{l}23.1 \\
(18.3 \text { to } 27.8)\end{array}$ & $\begin{array}{l}-13.2 \\
(-13.5 \text { to }-12.9)\end{array}$ & $\begin{array}{l}8.3 \\
(4.6 \text { to } 12.0)\end{array}$ & $\begin{array}{l}7.3 \\
(4.3 \text { to } 10.3)\end{array}$ & $\begin{array}{l}-1.0 \\
(-1.3 \text { to }-0.7)\end{array}$ \\
\hline 1960 & $\begin{array}{l}30.7 \\
(30.0 \text { to } 31.4)\end{array}$ & $\begin{array}{l}28.5 \\
(28.0 \text { to } 29.0)\end{array}$ & $\begin{array}{l}-2.2 \\
(-3.0 \text { to }-1.3)\end{array}$ & $\begin{array}{l}47.9 \\
(41.8 \text { to } 54.0)\end{array}$ & $\begin{array}{l}33.6 \\
(28.6 \text { to } 38.5)\end{array}$ & $\begin{array}{l}-14.3 \\
(-14.5 \text { to }-14.1)\end{array}$ & $\begin{array}{l}20.3 \\
(15.6 \text { to } 24.9)\end{array}$ & $\begin{array}{l}9.4 \\
(6.5 \text { to } 12.4)\end{array}$ & $\begin{array}{l}-10.9 \\
(-11.1 \text { to }-10.7)\end{array}$ \\
\hline 1970 & $\begin{array}{l}31.4 \\
(30.5 \text { to } 32.2)\end{array}$ & $\begin{array}{l}29.7 \\
(29.0 \text { to } 30.3)\end{array}$ & $\begin{array}{l}-1.7 \\
(-2.8 \text { to }-0.6)\end{array}$ & $\begin{array}{l}50.7 \\
(43.4 \text { to } 58.0)\end{array}$ & $\begin{array}{l}41.1 \\
\text { (35.8 to } 46.4)\end{array}$ & $\begin{array}{l}-9.6 \\
(-9.8 \text { to }-9.4)\end{array}$ & $\begin{array}{l}24.6 \\
(18.4 \text { to } 30.9)\end{array}$ & $\begin{array}{l}13.9 \\
(10.4 \text { to } 17.4)\end{array}$ & $\begin{array}{l}-10.7 \\
(-11.0 \text { to }-10.4)\end{array}$ \\
\hline \multicolumn{10}{|l|}{ Women } \\
\hline 1940 & $\begin{array}{l}27.5 \\
\text { (26.3 to } 28.7)\end{array}$ & $\begin{array}{l}27.5 \\
(26.6 \text { to } 28.4)\end{array}$ & $\begin{array}{l}0.0 \\
(-1.5 \text { to } 1.5)\end{array}$ & $\begin{array}{l}26.5 \\
(17.5 \text { to } 35.5)\end{array}$ & $\begin{array}{l}24.0 \\
(16.7 \text { to } 31.4)\end{array}$ & $\begin{array}{l}-2.5 \\
(-2.9 \text { to }-2.1)\end{array}$ & $\begin{array}{l}9.4 \\
(2.3 \text { to } 16.5)\end{array}$ & $\begin{array}{l}10.4 \\
(4.8 \text { to } 16.0)\end{array}$ & $\begin{array}{l}1.0 \\
(0.6 \text { to } 1.4)\end{array}$ \\
\hline 1950 & $\begin{array}{l}28.7 \\
\text { (27.9 to } 29.5)\end{array}$ & $\begin{array}{l}27.0 \\
(26.2 \text { to } 27.7)\end{array}$ & $\begin{array}{l}-1.7 \\
(-2.8 \text { to }-0.6)\end{array}$ & $\begin{array}{l}38.3 \\
\text { (31.4 to } 45.3)\end{array}$ & $\begin{array}{l}22.1 \\
(16.8 \text { to } 27.3)\end{array}$ & $\begin{array}{l}-16.2 \\
(-16.5 \text { to }-15.9)\end{array}$ & $\begin{array}{l}13.9 \\
(9.2 \text { to } 18.6)\end{array}$ & $\begin{array}{l}9.2 \\
(4.9 \text { to } 13.5)\end{array}$ & $\begin{array}{l}-4.7 \\
(-5.0 \text { to }-4.4)\end{array}$ \\
\hline 1960 & $\begin{array}{l}30.4 \\
(29.5 \text { to } 31.2)\end{array}$ & $\begin{array}{l}28.0 \\
(27.4 \text { to } 28.6)\end{array}$ & $\begin{array}{l}-2.4 \\
(-3.4 \text { to }-1.3)\end{array}$ & $\begin{array}{l}43.4 \\
(37.2 \text { to } 49.6)\end{array}$ & $\begin{array}{l}30.4 \\
(25.6 \text { to } 35.1)\end{array}$ & $\begin{array}{l}-13.0 \\
(-13.2 \text { to }-12.8)\end{array}$ & $\begin{array}{l}22.7 \\
(17.5 \text { to } 28.0)\end{array}$ & $\begin{array}{l}11.0 \\
(7.7 \text { to } 14.4)\end{array}$ & $\begin{array}{l}-11.7 \\
(-11.9 \text { to }-11.5)\end{array}$ \\
\hline 1970 & $\begin{array}{l}31.7 \\
\text { (30.4 to } 33.0 \text { ) }\end{array}$ & $\begin{array}{l}29.7 \\
(29.1 \text { to } 30.3)\end{array}$ & $\begin{array}{l}-2.0 \\
(-3.4 \text { to }-0.6)\end{array}$ & $\begin{array}{l}53.7 \\
(46.2 \text { to } 61.3)\end{array}$ & $\begin{array}{l}42.3 \\
\text { (37.3 to } 47.2 \text { ) }\end{array}$ & $\begin{array}{l}-11.4 \\
(-11.6 \text { to }-11.2)\end{array}$ & $\begin{array}{l}25.8 \\
(18.9 \text { to } 32.7)\end{array}$ & $\begin{array}{l}18.1 \\
\text { (14.1 to } 22.0)\end{array}$ & $\begin{array}{l}-7.7 \\
(-8.0 \text { to }-7.4)\end{array}$ \\
\hline
\end{tabular}

Numbers in brackets represent $95 \% \mathrm{Cl}$.

BMI, body mass index; SEP, socioeconomic position. 
disparities at age 60, when compared with the 1940 birth cohort.

\section{DISCUSSION}

Our study provides insight into the future inequalities in obesity and severe obesity in a high-income country. Persistent or widening inequalities were predicted between 1995 and 2025 for all birth cohorts studied. Moreover, the model predicted that recent birth cohorts will experience unprecedented levels of obesity and severe obesity by the time they reach middle age, and greater socioeconomic inequality, compared with earlier birth cohorts. Of great concern is the predicted shift towards inequality in severe obesity, and thus, the associated unequal burden of obesity-related disease.

The major strength of the study is our novel modelling methods which account for age-related BMI change across the life course and age-related mortality within SEP groups. BMI is modelled as a continuous variable, thus allowing for the prediction of prevalence of a range of weight status groups, including severe obesity, which has not previously been possible with existing models. ${ }^{30}$

Another strength is the validation of model projections using the most recently available national data on adult BMI from Australia. This provides confidence in the model's predictions into the future. We have adhered to good reporting practices for modelling ${ }^{27}$ and the modelling is comprehensive and transparent. Finally, the model is informed by objectively measured height and weight, based on nationally representative population data.

As with any modelling study, there are a number of assumptions. The first is that age-related and SEP-related annual weight gain derived from a contemporary time period, up to 2012, is assumed to hold beyond 2012. This may be a reasonable assumption, as recent studies suggest age-related annual weight gain has been stable or even slowed. ${ }^{22}{ }^{31}$ Another assumption is that there are no changes over time in the association between BMI and mortality among SEP groups. Nonetheless, in sensitivity analysis, we have investigated the scenarios of annual weight gain and the HR for mortality being higher or lower, and the major conclusions pertaining to the projected widening inequality in obesity and severe obesity prevalence still hold.

Another limitation of the study is the use of completion of high school education as the only indicator of SEP. As high school education is generally completed by early adulthood, it is a suitable indicator to use in an adult life course framework. ${ }^{32}$ There is evidence of education being an important predictor of weight gain ${ }^{33} 34$ and the use of an individual-level characteristic, is also consistent with microsimulation. However, the relevance of education as a marker of SEP may differ between birth cohorts because of secular trends in education levels. Interestingly, a recent meta-analysis ${ }^{35}$ using occupational status as a marker of SEP reported a very similar HR, for mortality of low compared with high SEP, to that used in our modelling, based on educational status. Other socioeconomic determinants such as household income, which may change over the life course, were not accounted for in the modelling. Investigations of inequalities in obesity progression using other measures of SEP will be an important avenue for future research. Finally, there were some missing data on education status, in our baseline population in 1995, particularly for the oldest birth cohort, which could lead to bias. However, our results show good internal and external validation, suggesting that any bias did not have major impact on the overall results.

To our knowledge, this is the first study in which a microsimulation model has been developed, validated and used to increase our understanding of trends in socioeconomic disparities in obesity among adults in Australia. This study adds to the debate of whether inequalities in obesity are growing. Our finding of widening inequalities in obesity corroborates with existing studies in the USA, ${ }^{7}$ UK, ${ }^{86}$ Australia $^{30}$ and Europe,${ }^{37}$ while other developed (Organisation for Economic Co-operation and Development) countries report stable inequalities, ${ }^{38}$ and a US study found that socioeconomic inequality in obesity had largely disappeared by $2012 .{ }^{39}$ The majority of these studies used traditional statistical analysis. In contrast, our dynamic model, which accounts for the association of weight gain and mortality with SEP, has allowed us to model into the future and hence to compare, side by side, four different birth cohorts of different SEP, born 10 years apart.

Socioeconomic disparities in obesity prevalence predicted by our model arise directly from the higher rate of weight gain among low compared with high SEP groups. Studies in other countries have also found disparities in weight gain by educational or occupational class. ${ }^{40}$ The mediators of inequalities in weight gain are not clear, but there is some evidence that diet quality is poorer for low SEP groups in Australia, ${ }^{42}$ and poorer health behaviours (smoking and physical activity) ${ }^{43}$ may also play a role. However, the presence of inequalities in obesity at the beginning of adulthood (figure 1) suggests inequalities in weight gain during childhood also contribute to inequalities in adulthood. The prediction that recent generations will have unprecedented levels of obesity and severe obesity by middle age is probably due to exposure to obesogenic environments, for a greater proportion of their lifetime, including wider access to low-nutrient, high-fat food and lower levels of physical activity.

Notably, the model predicted that socioeconomic inequalities in obesity will be greater than in previous generations, and that severe obesity, which has the greatest health implications and medical expenditures, ${ }^{4}$ will disproportionately affect those in lower SEP groups. This study fills an important gap in our understanding of how inequalities in obesity develop over time and has policy implications for targeting of prevention efforts. Lower SEP groups and more recent birth cohorts are 
at higher risk of obesity, severe obesity and its consequences in middle age. Prevention efforts should focus on these vulnerable population groups in order to avoid increasing disparities in the long-term burden of obesity in the future.

Beyond its use in predicting epidemiology of obesity within different social strata, this model is part of a wider research effort to develop a health economic model that has relevance for different SEP groups. As the epidemiological predictions of the model are sound, we can have high confidence in its health economic predictions. By modelling at the individual level, microsimulation will allow for the investigation of intervention effects targeted at specific population groups (eg, lower educated young men who are overweight). Simulation modelling has, to date, been underused in evaluation of the impact of interventions on inequalities in health. ${ }^{16}$ We hope future research using this model will assist policy-makers in identifying not only which interventions are most effective and cost-effective but will also determine which are most effective in narrowing the gap in socioeconomic disparities in overweight and obesity in adulthood.

Acknowledgements We thank the Australian Bureau of Statistics for provision of confidentialised unit record data pertaining to National Health Surveys.

Contributors The author's responsibilities were as follows: AH conceived the study. Model conceptualisation: AH and TL. Software: TL and AH. Analysed the data: AH, TL and EJT. Performed experiments: TL and EJT. Visualisation: AH, EJT and AK. Writing first draft: AH and AK. All authors revised the manuscript for important intellectual content. AH, EJT and TL had full access to the data and take responsibility for the integrity of the data analysis. $\mathrm{AH}$ is the guarantor. All authors have given final approval of the version to be published.

Funding EJT receives funding support from the National Health and Medical Research Council Centre of Research Excellence in Early Prevention of Obesity in Childhood (APP1101675). AK is supported by the Kassulke Scholarship for PhD study. TL is supported by a National Health and Medical Research Council Early Career Fellowship and a Heart Foundation Postdoctoral Fellowship (APP 1141392).

Competing interests None declared.

Patient consent for publication Not required.

Provenance and peer review Not commissioned; externally peer reviewed.

Data sharing statement The model code is available on request. Data on which analyses are based are available from the Australian Bureau of Statistics.

Open access This is an open access article distributed in accordance with the Creative Commons Attribution Non Commercial (CC BY-NC 4.0) license, which permits others to distribute, remix, adapt, build upon this work non-commercially, and license their derivative works on different terms, provided the original work is properly cited, appropriate credit is given, any changes made indicated, and the use is non-commercial. See: http://creativecommons.org/licenses/by-nc/4.0/.

\section{REFERENCES}

1. Bassett MT, Perl S. Obesity: the public health challenge of our time. Am J Public Health 2004;94:1477.

2. NCD Risk Factor Collaboration (NCD-RisC). Trends in adult bodymass index in 200 countries from 1975 to 2014: a pooled analysis of 1698 population-based measurement studies with $19 \cdot 2$ million participants. Lancet 2016;387:1377-96.

3. Australian Bureau of Statistics. National Health Survey: First Results, 2014-15. Canberra: Australian Bureau Statistics, 2015.

4. Kent S, Fusco F, Gray A, et al. Body mass index and healthcare costs: a systematic literature review of individual participant data studies. Obes Rev 2017;18:869-79.

5. McLaren L. Socioeconomic status and obesity. Epidemiol Rev 2007;29:29-48.
6. Korda RJ, Soga K, Joshy G, et al. Socioeconomic variation in incidence of primary and secondary major cardiovascular disease events: an Australian population-based prospective cohort study. Int $J$ Equity Health 2016;15:1-10.

7. Walsemann KM, Ailshire JA. BMI Trajectories During the Transition to Older Adulthood: Persistent, Widening, or Diminishing Disparities by Ethnicity and Education? Res Aging 2011;33:286-311.

8. Bann D, Johnson W, Li L, et al. Socioeconomic Inequalities in Body Mass Index across Adulthood: Coordinated Analyses of Individual Participant Data from Three British Birth Cohort Studies Initiated in 1946, 1958 and 1970. PLoS Med 2017;14:e1002214-20.

9. Zhu J, Coombs N, Stamatakis E. Temporal trends in socioeconomic inequalities in obesity prevalence among economically-active working-age adults in Scotland between 1995 and 2011: a population-based repeated cross-sectional study. BMJ Open 2015;5:e006739.

10. Zhang Q, Wang Y. Trends in the association between obesity and socioeconomic status in U.S. adults: 1971 to 2000. Obes Res 2004;12:1622-32.

11. Jacobsen BK, Njølstad I, Thune I, et al. Increase in weight in all birth cohorts in a general population: The Troms $\varnothing$ Study, 1974-1994. Arch Intern Med 2001;161:466-72.

12. Ward ZJ, Long MW, Resch SC, et al. Simulation of Growth Trajectories of Childhood Obesity into Adulthood. N Engl J Med 2017;377:2145-53.

13. Richardson MB, Williams MS, Fontaine KR, et al. The development of scientific evidence for health policies for obesity: Why and how? Int $J$ Obes 2017;41:840-8.

14. Smith BT, Smith PM, Harper S, et al. Reducing social inequalities in health: the role of simulation modelling in chronic disease epidemiology to evaluate the impact of population health interventions. J Epidemiol Community Health 2014;68:384-9.

15. Speybroeck N, Van Malderen C, Harper S, et al. Simulation models for socioeconomic inequalities in health: a systematic review. Int J Environ Res Public Health 2013;10:5750-80.

16. Levy DT, Mabry PL, Wang YC, et al. Simulation models of obesity: a review of the literature and implications for research and policy. Obes Rev 2011;12:378-94

17. Hayes AJ, Lung TW, Bauman A, et al. Modelling obesity trends in Australia: unravelling the past and predicting the future. Int $J$ Obes 2017;41:178-85.

18. Weinstein MC. Recent developments in decision-analytic modelling for economic evaluation. Pharmacoeconomics 2006;24:1043-53.

19. Australian Bureau of Statistics. Information Paper: National Nutrition Survey 1995 (Cat No. 4805.0. Canberra: Australian Bureau of Statistics, 1995.

20. Australian Bureau of Statistics. National Health Survey: Users' Guide - Electronic Publication, 2007-08 (Cat. No. 4363.0.55.001). Canberra: Australian Bureau of Statistics, 2008

21. Australian Bureau of Statistics. Australian Health Survey: First Results, 2011-12. Canberra: Australian Bureau of Statistics, 2012.

22. Hayes A, Gearon E, Backholer K, et al. Age-specific changes in BMI and $\mathrm{BMI}$ distribution among Australian adults using cross-sectional surveys from 1980 to 2008. Int J Obes 2015;39:1209-16.

23. Australian Government. Australian Life Tables 2010-12. Canberra Commonwealth of Australia. 2012 http://www.aga.gov.au/ publications/life table 2010-12/

24. Whitlock G, Lewington S, Sherliker P, et al. Body-mass index and cause-specific mortality in 900000 adults: collaborative analyses of 57 prospective studies. Lancet 2009;373:1083-96.

25. Bihan H, Backholer K, Peeters A, et al. Socioeconomic Position and Premature Mortality in the AusDiab Cohort of Australian Adults. Am J Public Health 2016;106:470-7.

26. Olshansky SJ, Passaro DJ, Hershow RC, et al. A potential decline in life expectancy in the United States in the 21st century. N Engl J Med 2005;352:1138-45

27. Caro JJ, Briggs $A H$, Siebert $U$, et al. Modeling good research practices--overview: a report of the ISPOR-SMDM Modeling Good Research Practices Task Force--1. Value Health 2012;15:796-803.

28. Goya Wannamethee S, Gerald Shaper A, Whincup PH, et al. Overweight and obesity and the burden of disease and disability in elderly men. Int J Obes Relat Metab Disord 2004;28:1374-82.

29. Weinstein MC, O'Brien B, Hornberger J, et al. Principles of good practice for decision analytic modeling in health-care evaluation: report of the ISPOR Task Force on Good Research Practices-Modeling Studies. Value Health 2003;6:9-17.

30. Backholer K, Mannan HR, Magliano DJ, et al. Projected socioeconomic disparities in the prevalence of obesity among Australian adults. Aust N Z J Public Health 2012;36:557-63.

31. Peeters A, Magliano DJ, Backholer K, et al. Changes in the rates of weight and waist circumference gain in Australian adults over time: a longitudinal cohort study. BMJ Open 2014;4:e003667. 
32. Galobardes B, Lynch J, Smith GD. Measuring socioeconomic position in health research. Br Med Bull 2007;81-82:21-37.

33. Ball K, Crawford D, Ireland P, et al. Patterns and demographic predictors of 5-year weight change in a multi-ethnic cohort of men and women in Australia. Public Health Nutr 2003;6:269-80.

34. Ball K, Crawford D. Socioeconomic status and weight change in adults: a review. Soc Sci Med 2005;60:1987-2010.

35. Stringhini S, Carmeli C, Jokela M, et al. Socioeconomic status and the $25 \times 25$ risk factors as determinants of premature mortality: a multicohort study and meta-analysis of 1.7 million men and women. Lancet 2017;389:1229-37.

36. Zaninotto P, Head J, Stamatakis E, et al. Trends in obesity among adults in England from 1993 to 2004 by age and social class and projections of prevalence to 2012. J Epidemiol Community Health 2009;63:140-6.

37. Hoffmann K, De Gelder R, Hu Y, et al. Trends in educational inequalities in obesity in 15 European countries between 1990 and 2010. Int J Behav Nutr Phys Act 2017;14:1-10.

38. Devaux M, Sassi F. Social inequalities in obesity and overweight in 11 OECD countries. Eur J Public Health 2013;23:464-9.
39. Bilger M, Kruger EJ, Finkelstein EA. Measuring socioeconomic inequality in obesity: looking beyond the obesity threshold. Health Econ 2017;26:1052-66.

40. Shaw RJ, Green MJ, Popham F, et al. Differences in adiposity trajectories by birth cohort and childhood social class: evidence from cohorts born in the 1930s, 1950s and 1970s in the west of Scotland. J Epidemiol Community Health 2014;68:550-6.

41. Clarke P, O'Malley PM, Johnston LD, et al. Social disparities in BMI trajectories across adulthood by gender, race/ethnicity and lifetime socio-economic position: 1986-2004. Int J Epidemiol 2009;38:499-509.

42. Grech A, Sui Z, Siu H, et al. Socio-Demographic Determinants of Diet Quality in Australian Adults Using the Validated Healthy Eating Index for Australian Adults (HEIFA-2013). Health Care 2017;5:7-12.

43. Williams ED, Tapp RJ, Magliano DJ, et al. Health behaviours, socioeconomic status and diabetes incidence: the Australian Diabetes Obesity and Lifestyle Study (AusDiab). Diabetologia 2010;53:2538-45. 